\title{
Stability, compatibility and microbiological activity studies of meropenem-clavulanate potassium
}

\author{
Judyta Cielecka-Piontek ${ }^{1}$, Daria Szymanowska-Powałowska ${ }^{2}$, Magdalena Paczkowska $^{1}$, Piotr Łysakowski ${ }^{2}$, \\ Przemysław Zalewski ${ }^{1}$ and Piotr Garbacki ${ }^{1}$
}

Meropenem (MEM) and clavulanate potassium have been reported to demonstrate highly effective activity against Mycobacterium tuberculosis. There have been no reports on research into the complex of these chemotherapeutics concerning their mutually dependent stability or microbiological action on other microorganisms. Stability and compatibility studies of MEM/clavulanate potassium were conducted by using an HPLC-DAD method. The antibacterial activity of MEM/clavulanate potassium was tested in vitro against a selection of indicator bacteria strains by determining the MIC as well as analyzing the kinetics of changes in the concentrations of Pseudomonas aeruginosa, Staphylococcus aureus and Listeria monocytogenes caused by the action of MEM/clavulanate potassium. The stability and compatibility of MEM/clavulanate potassium were examined in aqua pro iniectione, $0.9 \% \mathrm{NaCl}$ and $5 \%$ glucose at room temperature and at $5{ }^{\circ} \mathrm{C}$. The degradation rates of MEM/clavulanate potassium depended on the type of infusion solvent used. Although in aqueous solutions of MEM/clavulanate potassium neither compound showed any mutual impact on the rate of degradation, clavulanate potassium was more labile than MEM. The synergy between these two resulted in a significantly lower value of MIC as compared to the values observed for the individual activity of either compound. The infusion solvent in which compatibility is observed between the components of the mixture MEM/clavulanate potassium is aqua pro iniectione. The complex MEM/clavulanate potassium demonstrates synergic antibacterial activity against $P$. aeruginosa, $S$. aureus and $L$. monocytogenes.

The Journal of Antibiotics (2015) 68, 35-39; doi:10.1038/ja.2014.92; published online 30 July 2014

\section{INTRODUCTION}

Meropenem (MEM; Figure 1) is the most common drug of all carbapenems used in the treatment of bacterial infections and shows the greatest therapeutic safety, also regarding neurotoxicity. ${ }^{1-4}$ The application of carbapenems, including MEM, is often limited by their susceptibility to degradation under the influence of carbapenemases and due to the effect of efflux. ${ }^{5}$ Carbapenemases, belonging to the molecular class A, are mainly produced by Enterobacteriaceae and non-fermenter bacteria, which results in an increasing bacterial resistance to carbapenems, including MEM. ${ }^{6}$

Clavulanate acid (CA; Figure 1 ) is the first clinically useful $\beta$-lactam inhibitor with a high affinity for the class A $\beta$-lactamase ${ }^{7-10}$ and, in effect, an irreversible inhibitor of intracellular and extracellular $\beta$-lactamases. Consequently, combinations of CA with penam analogs (amoxicillin) are widely used to treat bacterial infections of various etiology.

Recent studies indicated that the complex MEM/clavulanate potassium was highly effective in the treatment of infections with Mycobacterium tuberculosis, including multidrug-resistant and extensively drug-resistant tuberculosis. ${ }^{11-16}$ Moreover, it was reported that in the presence of clavulanic acid, MIC values of MEM against
Klebsiella oxytoca and Eschierichia coli transformants significantly decreased. ${ }^{17}$ However, no research on the mutual compatibility of MEM and clavulante potassium has been published.

It must be remembered that the presence of coupled rings in MEM and in clavulanic acid generates intraring stress which is responsible for the considerable instability of those compounds (Figure 2). Both MEM and clavulanic acid have frequently been proved very unstable in aqueous solutions (including infusion solutions) and in the solid phase. ${ }^{18-21}$ The catalytic effect of degradants on the degradation of clavulanic acid and the influence of excipients on the stability of MEM have also been described. ${ }^{22,23}$

The aim of this work was to investigate the stability and compatibility of MEM and clavulanate potassium in selected infusion solvents and to determine the microbiological activity of the complex $\mathrm{MEM} /$ clavulanate potassium.

\section{RESULTS AND DISCUSSION}

Since the recommended solvents for MEM infusions are $0.9 \% \mathrm{NaCl}$, $5 \%$ glucose or aqua pro iniectione while clavulanate potassium should be dissolved in aqua pro iniectione or a $0.9 \% \mathrm{NaCl}$ solution, ${ }^{24,25}$ the stability and compatibility of MEM/clavulanate potassium

${ }^{1}$ Department of Pharmaceutical Chemistry, Faculty of Pharmacy, Poznan University of Medical Sciences, Poznań, Poland and ${ }^{2}$ Department of Biotechnology and Food Microbiology, Poznan University of Life Sciences, Poznań, Poland

Correspondence: Dr J Cielecka-Piontek, Department of Pharmaceutical Chemistry, Faculty of Pharmacy, Poznan University of Medical Sciences, Grunwaldzka 6, Poznan 60-780, Poland.

E-mail: jpiontek@ump.edu.pl

Received 3 November 2013; revised 30 May 2014; accepted 18 June 2014; published online 30 July 2014 
were studied in aqua pro iniectione, $0.9 \% \mathrm{NaCl}$ and $5 \%$ glucose solutions. The concentrations of MEM ( $50 \mathrm{mg} \mathrm{ml}^{-1}$ ) and clavulanate potassium $\left(1.66 \mathrm{mg} \mathrm{ml}^{-1}\right)$ were the same as those for infusions of the individual chemotherapeutics. The ratio of MEM to clavulanate potassium was 5:1 and corresponded to the MEM/clavulanate potassium ratio for which the mixture proved active against M. tuberculosis. ${ }^{11-16}$ An analysis of changes in the concentrations of MEM and clavulanate potassium showed that their values fell below $95 \%$ of the initial values at different time intervals depending on the solvent used (Table 1). The desired level of stability over a period of $2.0 \mathrm{~h}$ was demonstrated by MEM and clavulanate potassium after their dissolution in aqua pro iniectione. Also, in that solvent the two compounds did not exhibit any mutually negative impact on stability after their use for the preparation of a two-drug infusion solution. In the other solutions, MEM and clavulanate potassium were less stable in their mutual presence, which may be explained by the possible catalytic effect of degradation products. $^{21-23}$ The MEM and clavulanate potassium were more susceptible to degradation in $0.9 \% \mathrm{NaCl}$ and therefore it should not be recommended as a solvent. It was also observed that the application of $5 \%$ glucose can cause uncontrolled hydrolysis of MEM, depending on the $\mathrm{pH}$ of the solution. The greater stability of MEM in combination with clavulanate potassium in $5 \%$ glucose merits considering changes in the acid $\mathrm{pH}$ resulting from the presence of the potassium salt and, consequently, the slowing of hydrolysis of the $\beta$-lactam ring in MEM. As the concentrations of MEM and clavulanate potassium changed, the infusion solutions assumed a different color. The solutions that were refrigerated (at $5{ }^{\circ} \mathrm{C}$ ) demonstrated greater stability (Table 1) than those stored at room temperature. The next step in this work involved a range of microbiological tests aimed at investigating the influence of active substances on selected strains of indicator microorganisms. Strains from bacterial strain bank as well as clinical isolates were used in the study. First, the MICs were determined for all strains (Table 2). For four examined strains the synergistic antimicrobial effect of MEM + CA solution was observed. Among examined strains, the synergy of MEM $+\mathrm{CA}$ was not observed on Salmonella enteritidis and Clostridium butyricum. What is more, the MIC for C. butyricum increased. It is suspected that the reason standing behind this phenomenon is the lack of impact of clavulanate potassium on these strains. Among examined model strains, the lowest inhibitory concentration of MEM was observed for C. pasterianum ATCC 6013 and S. aureus ATCC 25923; 0.125 and $0.25 \mathrm{mgl}^{-1}$, respectively. In these cases an increase of antimicrobial activity of MEM + CA was again noted. Table 2 shows

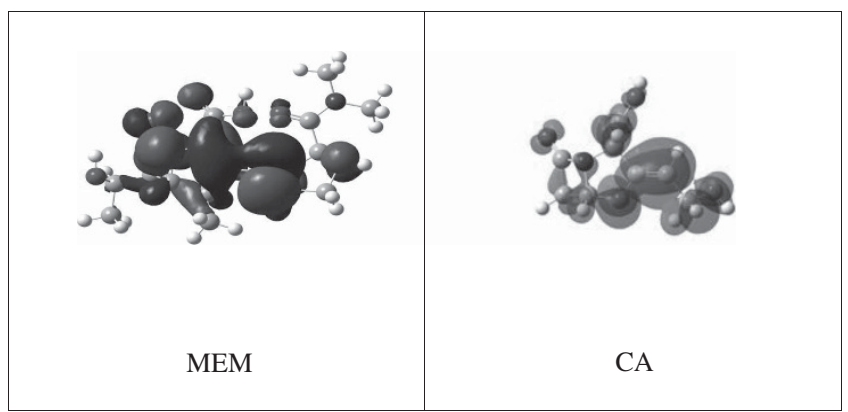

Figure 1 Equilibrium geometry of meropenem (MEM) and clavulanate acid (CA) optimized by means of a density functional theory (DFT) method with the B3LYP hybrid functional and a $6-31 \mathrm{G}(\mathrm{d}, \mathrm{p})$ basis set. A full color version of this figure is available at The Journal of Antibiotics journal online. that clinical isolates are more resistant to MEM and CA, which is certainly connected to hospital-acquired resistance to various antibiotics.

Among clinical isolates, the lowest MIC of $2 \mathrm{mgl}^{-1} \mathrm{MEM}$ was observed for $S$. aureus, whereas the lowest MIC for CA was $4 \mathrm{mgl}^{-1}$. While MEM and CA were used simultaneously, MICs for this strain dropped to $0.2 \mathrm{mgl}^{-1}$. Similar observation was made for L. monocytogenes. Substantial decrease of MIC while using MEM + CA was observed for $P$. aeruginosa. MIC of MEM $=16 \mathrm{mgl}^{-1}$ and $\mathrm{MIC}$ for $\mathrm{CA}=32$ were reduced to $1 \mathrm{mgl}^{-1}$ for $\mathrm{MEM}+\mathrm{CA}$. The inhibitory effect of the MEM/clavulanic acid complex on the growth of pathogenic bacteria has been reported by other authors as well. Their research mainly concerned $M$. tuberculosis. England et al. ${ }^{14}$ found a decrease in the number of living cells of that species following administration of the MEM + CA complex to infected mice.

For three species (clinical isolates) with the highest susceptibility to the MEM + CA solution (P. aeruginosa, S. aureus and L. monocytogenes) an observation of growth kinetics was performed. In this experiment the MIC was used for each species (Table 2). The experiment results are shown in Figure 2. The number of living $P$. aeruginosa cells started to decrease $4 \mathrm{~h}$ after addition of the $\mathrm{MEM}+\mathrm{CA}$ solution. After $24 \mathrm{~h}$ the number of living cells was reduced from $6.8 \times 10^{5}$ to $2.1 \times 10^{3} \mathrm{CFU} \mathrm{ml}{ }^{-1}$. Thus, $P$. aeruginosa appeared to be the most susceptible to the drugs tested. A significant reduction in the number of $S$. aureus living cells was registered after $12 \mathrm{~h}$. The initial value $4.0 \times 10^{5} \mathrm{CFU} \mathrm{ml}^{-1}$ dropped to $3.2 \times$ $10^{3} \mathrm{CFU} \mathrm{ml}^{-1}$ after $48 \mathrm{~h}$. The decrease of L. monocytogenes live-cell count started $8 \mathrm{~h}$ after addition of the antibiotics. The initial number of living cells $\left(3.8 \times 10^{5} \mathrm{CFU} \mathrm{ml}^{-1}\right)$ diminished to $6.0 \times$ $10^{3} \mathrm{CFU} \mathrm{ml}^{-1}$ after $48 \mathrm{~h}$. However, the biggest decrease of cells was observed in the first $24 \mathrm{~h}$. The microorganisms entered the death phase after $96 \mathrm{~h}$.

\section{CONCLUSIONS}

The complex MEM/clavulanate potassium may be a valuable solution for the treatment of certain bacterial infections. The infusion solvent in which compatibility was found between the components of the mixture of MEM and clavulanate potassium was aqua pro iniectione. However, due to the considerable instability of those two compounds the infusion must be administered strictly within the prescribed time after preparation, regarding clavulanate potassium as the more unstable component of the mixture. The complex formed by MEM and clavulanate potassium demonstrates synergic antibacterial action on certain strains of bacteria. On the basis of literature data, it is suspected that lower values of MIC shown by the complex compared to the individual components result from the inhibition of class A carbapenemases, however the effect of efflux cannot be excluded in view of the significant bactericidal efficacy of MEM/clavulanate potassium against Pseudomonas spp.

\section{METHODS}

\section{Antibacterial agents}

MEM and clavulanic acid potassium salt were provided by Chemos $\mathrm{GmbH}$ (Regenstauf, Germany). MEM had a purity of $98 \%$, while clavulante potassium contained less than $0.4 \%$ polymeric impurities and other impurities (E, G). All other chemicals and solvents used in the stability and compatibility studies were obtained from Merck KGaA (Darmstadt, Germany) and were of analytical grade. The reagents and indicator bacteria were obtained from Biocorp (Warsaw, Poland). High-quality pure water was prepared using an Exil SA 67120 purification system (Millipore, Molsheim, France). 


\section{a}

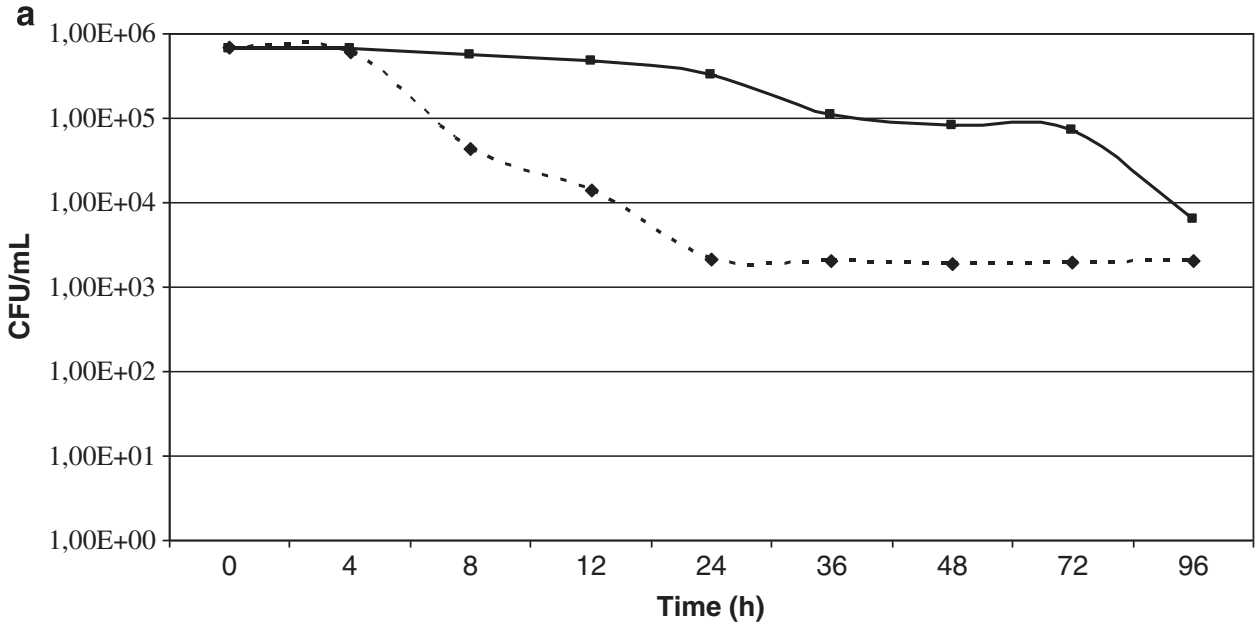

b
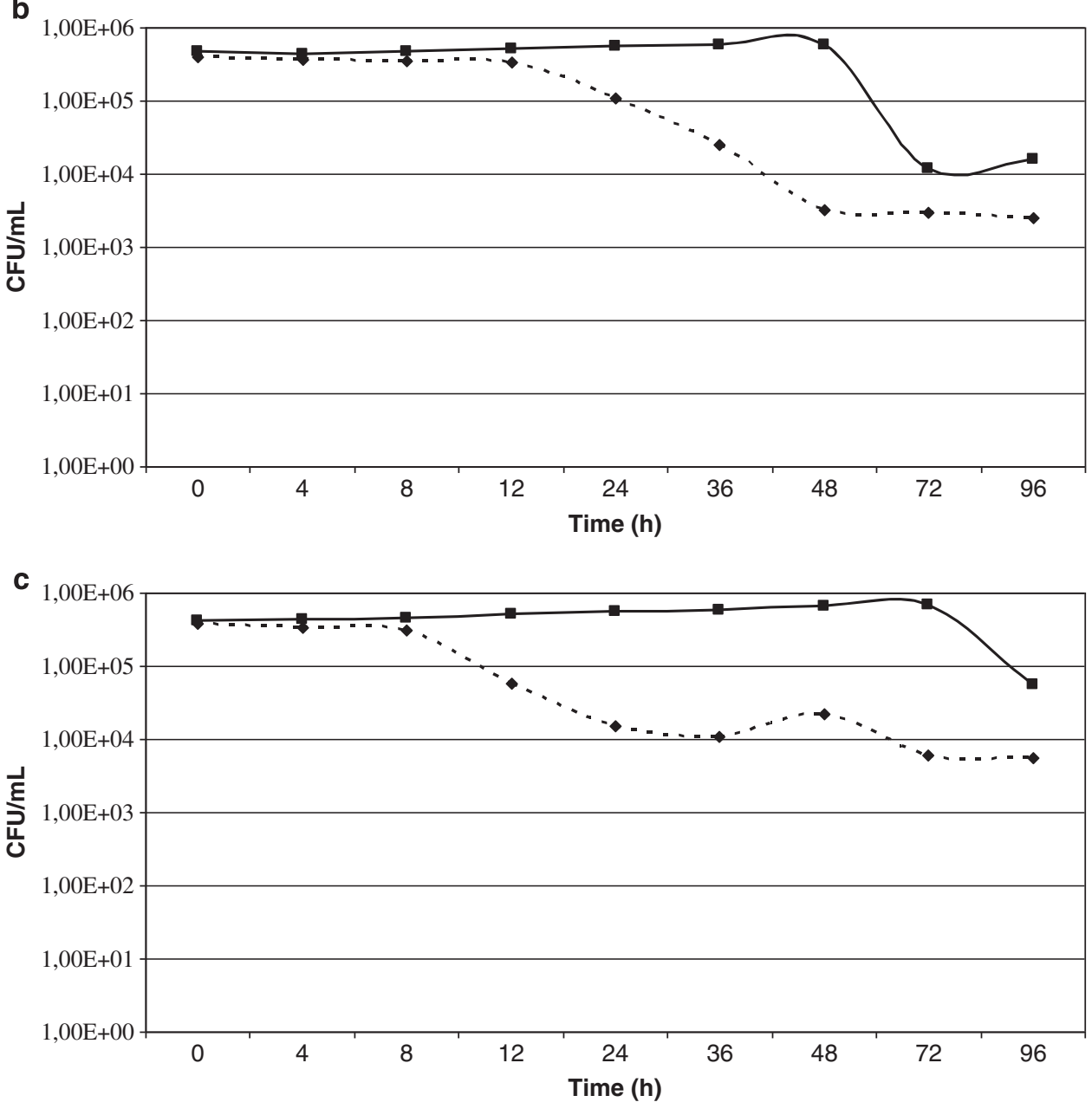

Figure 2 Number of Pseudomonas aeruginosa (a) Staphylococcus aureus (b) and Listeria monocytogenes (c) cells during incubation with solution of meropenem/clavulanate potassium. Broken line, culture with meropenem/clavulante potassium; continuous line, culture without meropenem/clavulante potassium.

\section{MEM-clavulante potassium assay}

Changes in the concentration of MEM and clavulanate potassium in infusion solutions were studied by using an HPLC-DAD method with the following set-up: an RP-18 column, the mobile phase consisting of a mixture of solutions A ( $12 \mathrm{mmoll}^{-1}$ ammonium acetate) and B (acetonitrile) with an initial composition of $4 \%$ solution $\mathrm{B}$ and the flow rate $1.0 \mathrm{ml} \mathrm{min}^{-1}$.
The wavelength of the DAD detector was 298 and $220 \mathrm{~nm}$ for MEM and clavulanate potassium, respectively. The method was validated with regard to linearity, precision, accuracy, limit of detection (LOD) and limit of quantification (LOQ). ${ }^{26}$ All quality control solutions were run with each series of assays. Each sample was assayed at least three times and the data were pooled. 
Table 1 Stability and compatibility studies of meropenem/clavulante potassium

\begin{tabular}{|c|c|c|c|c|c|}
\hline Time (h) & $\begin{array}{l}\text { Content of } \\
\text { MEM (\%) }\end{array}$ & $\begin{array}{c}\text { Content } \\
\text { of CP (\%) }\end{array}$ & $\begin{array}{c}\text { Content of MEM } \\
\text { in presence } \\
\text { of } C P(\%)\end{array}$ & $\begin{array}{c}\text { Content of } C P \\
\text { in presence of } \\
M E M(\%)\end{array}$ & $\begin{array}{c}\text { Compatibility } \\
\text { of MEM } \\
\text { and } C P\end{array}$ \\
\hline \multicolumn{6}{|c|}{ Aqua pro iniectione, $R T$} \\
\hline 0 & 100.00 & 100.00 & 100.00 & 100.00 & \\
\hline 2 & 93.49 & 90.08 & 96.16 & 94.52 & US, C \\
\hline 4 & 87.57 & 85.65 & 89.06 & 92.01 & US, C \\
\hline 6 & 85.30 & 84.73 & 85.76 & 84.81 & US, C \\
\hline \multicolumn{6}{|c|}{$0.9 \% \mathrm{NaCl}, \mathrm{RT}$} \\
\hline 0 & 100.00 & 100.00 & 100.00 & 100.00 & \\
\hline 2 & 95.51 & 94.41 & 95.03 & 91.76 & US, IC \\
\hline 4 & 91.01 & 83.73 & 88.14 & 80.21 & US, IC \\
\hline 6 & 84.81 & 79.48 & 79.32 & 79.41 & US, IC \\
\hline \multicolumn{6}{|c|}{$5 \%$ Glucose, $R T$} \\
\hline 0 & 100.00 & 100.00 & 100.00 & 100.00 & \\
\hline 2 & 71.33 & 96.64 & 94.55 & 84.09 & US, IC \\
\hline 4 & 69.32 & 59.58 & 86.62 & 80.80 & US, C \\
\hline 6 & 50.26 & 49.95 & 80.17 & 77.00 & US, C \\
\hline \multicolumn{6}{|c|}{ Aqua pro injectione, $5^{\circ} \mathrm{C}$} \\
\hline 0 & 100.00 & 100.00 & 100.00 & 100.00 & \\
\hline 2 & 97.78 & 95.97 & 99.97 & 97.64 & $S, C$ \\
\hline 4 & 93.65 & 93.11 & 96.85 & 95.85 & S, C \\
\hline 6 & 94.93 & 89.98 & 95.28 & 87.48 & US, C \\
\hline \multicolumn{6}{|c|}{$0.9 \% \mathrm{NaCl} 5^{\circ} \mathrm{C}$} \\
\hline 0 & 100.00 & 100.00 & 100.00 & 100.00 & \\
\hline 2 & 99.45 & 90.98 & 99.00 & 97.66 & $S, C$ \\
\hline 4 & 90.82 & 88.42 & 90.05 & 96.28 & US, C \\
\hline 6 & 85.47 & 86.44 & 84.41 & 89.23 & US, C \\
\hline \multicolumn{6}{|c|}{$5 \%$ Glucose $5^{\circ} \mathrm{C}$} \\
\hline 0 & 100.00 & 100.00 & 100.00 & 100.00 & \\
\hline 2 & 82.32 & 97.73 & 95.99 & 97.40 & US, C \\
\hline 4 & 79.53 & 94.53 & 86.51 & 83.21 & US, C \\
\hline 6 & 69.40 & 96.19 & 71.84 & 78.41 & US, C \\
\hline
\end{tabular}

Abbreviations: C, chemically and physically compatible; CP, clavulanate potassium; IC, chemically and physically incompatible; MEM, meropenem; RT, room temperature; S, stable US, unstable.

Stability and compatibility studies of MEM/clavulanate potassium The injection solvents selected for the stability and compatibility studies of MEM/ clavulanate potassium were aqua pro iniectione, a $5 \%$ solution of glucose and a $0.9 \%$ solution of $\mathrm{NaCl}$, prepared under sterile conditions. The initial concentrations of MEM $\left(50 \mathrm{mg} \mathrm{ml}^{-1}\right)$ and clavulanate potassium $\left(1.66 \mathrm{mg} \mathrm{ml}^{-1}\right)$ corresponded to those recommended by the manufacturers for application in monotherapy with the drugs studied. The ratio of MEM to clavulanic acid in the injection samples was 1:5. The stability tests were performed at room temperature $\left(25^{\circ} \mathrm{C}\right)$ and at $5{ }^{\circ} \mathrm{C}$. Solutions of MEM and clavulanate potassium were defined as stable when the non-degraded content of either therapeutic was greater than $95 \%$ at a specified time, where the reference value was the concentration of either analyte on dissolving in the infusion solvent.

\section{Preparation of indicator microorganisms}

Strains from bacterial strain bank (ATCC numbers in Table 2) as well as clinical isolates were used in the study. Cultures of $P$. aeruginosa, L. monocytogenes, S. enteritidis, S. aureus and E. coli were cultured in soycaseine broth with yeast extract for microorganisms with increased nutritional
Table 2 In vitro activity of meropenem/clavulanate potassium against Gram-negative and Gram-positive pathogens

\begin{tabular}{|c|c|c|c|}
\hline Indicator microorganisms & $\begin{array}{c}\text { Meropenem } \\
\left(m g /^{-1}\right)\end{array}$ & $\begin{array}{c}\text { Clavulanate } \\
\text { potassium } \\
\left(m g l^{-1}\right)\end{array}$ & $\begin{array}{c}\text { Meropenem/ } \\
\text { clavulanate } \\
\text { potassium } \\
\left(m g l^{-1}\right)\end{array}$ \\
\hline Salmonella enteritidis ${ }^{a}$ & 250 & NF & 250 \\
\hline $\begin{array}{l}\text { Salmonella enteritidis } \\
\text { ATCC } 13076\end{array}$ & 32 & NF & 32 \\
\hline Listeria monocytogenes ${ }^{a}$ & 4 & 1 & 0.2 \\
\hline $\begin{array}{l}\text { Listeria monocytogenes } \\
\text { ATCC } 7644\end{array}$ & 2 & 1 & 0.02 \\
\hline Staphylococcus aureus ${ }^{a}$ & 2 & 4 & 0.2 \\
\hline $\begin{array}{l}\text { Staphylococcus aureus } \\
\text { ATCC } 25923\end{array}$ & 0.25 & 1 & 0.2 \\
\hline Escherichia colp & 4 & 32 & 4 \\
\hline $\begin{array}{l}\text { Escherichia coli ATCC } \\
25922\end{array}$ & 4 & 16 & 1 \\
\hline Pseudomonas aeruginosa ${ }^{a}$ & 16 & 32 & 1 \\
\hline $\begin{array}{l}\text { Pseudomonas aeruginosa } \\
\text { ATCC } 27853\end{array}$ & 8 & 32 & 4 \\
\hline Clostridium butyricum ${ }^{\text {a }}$ & 4 & NF & 8 \\
\hline $\begin{array}{l}\text { Clostridium butyricum } \\
\text { ATCC } 860\end{array}$ & 4 & NF & 16 \\
\hline Clostridium pasterianum ${ }^{a}$ & 16 & 8 & 16 \\
\hline $\begin{array}{l}\text { Clostridium pasterianum } \\
\text { ATCC } 6013\end{array}$ & 0.125 & 8 & 4 \\
\hline
\end{tabular}

requirements. C. butyricum and C. pasterianum were grown in Reinforced Clostridial Medium (RCM, Oxoid, UK). The strains came from the collection of the Department of Biotechnology and Food Microbiology, University of Life Sciences, Poznan, Poland, and American Type Culture Collection.

\section{Determination of MICs of MEM and clavulanate potassium}

MICs were determined in liquid medium using successive dilutions method. The concentrations of the MEM, CA and MEM + CA solutions were lowered to $0.02-250 \mathrm{mgl}^{-1}$. The ratio of MEM to clavulanic acid in the injection samples was 5:1. First, test tubes with liquid medium for bacteria were prepared. Then MEM, CA or MEM + CA solutions of decreasing concentrations were added to each of test tubes. Next, test tubes were inoculated with the same amount of cells suspension. After $16-18 \mathrm{~h}$ of incubation in $37^{\circ} \mathrm{C}$, the growth of strains was checked via turbidity increase observation. In test tubes containing less than MIC of examined drugs, the turbidity increase was observed (the cells have grown). The minimal concentration of drug/s that inhibited strain growth was defined as MIC.

\section{Observation of growth kinetics of indicator bacteria ( $S$. aureus, $L$. monocytogenes and $P$. aeruginosa) during incubation with MEM and CA}

The indicator microorganisms (clinical isolates) were cultured under aerobic conditions $\left(37^{\circ} \mathrm{C}, 24 \mathrm{~h}\right)$ in soy-caseine broth with yeast extract. After proliferation, the MEM $+\mathrm{CA}$ solutions were added. Each microorganism received its MIC of the MEM + CA solution. The cultures were run at $37^{\circ} \mathrm{C}$ for $96 \mathrm{~h}$. Samples were collected after 0, 4, 8, 12, 24, 36, 48, 72 and $96 \mathrm{~h}$. The number of bacteria was determined via the pour plate method. Agar with cetrimide, fucidin and cephaloridine, ALOA Agar and Baird-Parker RPF mediums were used for $P$. aeruginosa, L. monocytogenes and $S$. aureus, respectively. The mediums were prepared in accordance with the manufacturer's (BTL, Łódź, Poland and Oxoid, UK) instructions. 
1 Drusano, G., Lode, H. \& Edwards, J. R. Meropenem: clinical response in relation to in vitro susceptibility. Clin. Microb. Infec. 6, 184-194 (2000).

2 Papp-Wallace, K., Endimiani, A., Taracila, M. \& Bonomo, R. Carbapenems: past, present, and future. Antimicrob. Agents Chemother. 55, 4943-4960 (2011).

3 Gupta, N., Limbago, B., Patel, J. \& Kallen, A. Carbapenem-Resistant Enterobacteriaceae: epidemiology and prevention. Clin. Infect. Dis. 53, 60-67 (2011).

4 Norrby, S. R. Neurotoxicity of carbapenem antibiotics: consequences for their use in bacterial meningitis. J. Antimicrob. Chemother. 45, 5-7 (2000).

5 Giske, C. G., Buaro, L., Sundsjord, A. \& Wretlind, B. Alterations of porin, pumps, and penicillin-binding proteins in carbapenem resistant clinical isolates of Pseudomonas aeruginosa. Microb. Drug Resist. 14, 23-30 (2008).

6 Woodford, N. et al. Outbreak of Klebsiella pneumoniae producing a new carbapenemhydrolyzing class $\beta$-lactamase, KPC-3, in a New York Medical Center. Antimicrob. Agents Chemother. 48, 4793-4799 (2004).

7 Finlay, J., Miller, L. \& Poupard, J. A. A review of the antimicrobial activity of clavulanate. J. Antimicrob. Chemother. 52, 18-23 (2003).

8 Saudagar, P., Survase, S. \& Singhal, R. Clavulanic acid: a review. Biotech. Adv. 26, 335-351 (2008).

9 Payne, D., Cramp, R., Winstanley, D. \& Knowles, D. Comparitive activites of clavulanic acid, sulbactam and tazobactam against clinically important $\beta$-lactamases. Antimicrob. Agents Chemother. 38, 767-772 (1994).

10 Higgins, P., Wisplinghoff, H., Stefanik, D. \& Seifert, H. In vitro activies of the $\beta$-lactamase inhibitors clavulanic acid, sulbactam and tazobactam alone or in combination with $\beta$-lactams against epidemiologically characterized multidrugresistant Acinetobacter Baumannii strains. Antimicrob. Agents Chemother. 48, 1586-1592 (2004).

11 Gonzalo, X. \& Drobniewski, F. Is there a place for $\beta$-lactams in the treatment of multidrug-resistant/extensively drug-resistant tuberculosis? Synergy between meropenem and amoxicillin/clavulanate. J. Antimicrob. Chemother. 68, 366-369 (2013).

12 Veziris, N., Truffot, C., Mainardi, J. L. \& Jarlier, V. Activity of carbapenems combined with clavulanate against murine tuberculosis. Antimicrob. Agents Chemother. 55, 2597-2600 (2011).

13 Hugonnet, J. E., Tremblay, L. W., Boshoff, H. I., Barry, C. E. 3rd \& Blanchard, J. S. Meropenem-clavulanate is effective against extensively drug-resistant Mycobacterium tuberculosis. Science 27, 1215-1218 (2009).
14 England, K. et al. Activity against Mycobacterium tuberculosis in vivo. Antimicrob. Agents Chemother. 56, 3384-3387 (2012).

15 Payen, M. C. et al. Clinical use of the meropenem-clavulanate combination for extensively drug-resistant tuberculosis. Int. J. Tuberc. Lung Dis. 16, 558-560 (2012).

16 Schermann, M. et al. Drug targeting Mycobacterium tuberculosis cell wall synthesis: development of a microtiter plate-based screen for UDP-galactopyronose mutase and identification of an inhibitor from a uridine-based library. Antimicrob. Agents Chemother. 47, 378-382 (2003).

17 Yigit, $\mathrm{H}$. et al. Carbapenem-resistant strain of Klebsiella oxytoca harboring carbapenem-hydrolizing $\beta$-lactamase KPC-2. Antimicrob. Agents Chemother. 47, 3881-3889 (2003).

18 Cielecka-Piontek, J., Michalska, K., Zalewski, P. \& Jelińska, A. Recent advances in stability studies of carbapenems. Curr. Pharm. Anal. 7, 213-227 (2011).

19 Cielecka-Piontek, J., Michalska, K., Zalewski, P. \& Zasada, S. Comparative review of analytical techniques for determination of carbapenems. Curr. Anal. Chem. 8, 91-115 (2012).

20 Jarurantanarirkul, S. \& Sriwriyajan, S. Stability of meropenem in normal saline solution after storage at room temperature. Southeast Asian J. Trop. Med. Public Health 34 627-629 (2003)

21 Berthoin, K., Duff, C., Marchand-Brynaert, J., Carryn, S. \& Tylkens, P. Stability of meropenem and doripenem solutions for administration by continuous infusion. J. Antimicrob. Chemother. 65, 1073-1075 (2010).

22 Santos, V. et al. Stability of clavulnic acid under variable $\mathrm{pH}$, ionic strength and temperature conditions. A new kinetic approach. Biochem. Eng. J. 45, 89-93 (2009).

23 Mendez, A., Dalomo, J., Steppe, M. \& Schapoval, E. Stability and degradation kinetics of meropenem in powder for injection and reconstituted sample. J. Pharm. Biomed. Anal. 41, 1363-1366 (2006).

24 RxList-The Internet Drug Index for Prescription Drugs and Medications. The Internet Drug Index http://www.rxlist.com/merrem-iv-drug.htm. Accessed 2 June (2014)

25 RxList-The Internet Drug Index for Prescription Drugs and Medications. The Internet Drug Index http://www.rxlist.com/timentin-injection-drug.htm. Accessed 2 June (2014)

26 Zalewski, P., Cielecka-Piontek, J. \& Paczkowska, M. Development and validation of stability-indicating HPLC method for simultaneous determination of meropenem and clavulanate potassium. Acta Pol. Pharm. 71, 55-60 (2014). 